\title{
Modeling Analysis and Improvement of Power Loss in Microgrid
}

\author{
H. Lan, ${ }^{1}$ S. Wen, ${ }^{1}$ Q. Fu, ${ }^{2}$ D. C. Yu, ${ }^{2}$ and L. Zhang ${ }^{1}$ \\ ${ }^{1}$ College of Automation, Harbin Engineering University, Harbin 150001, China \\ ${ }^{2}$ Department of Electrical Engineering and Computer Science, University of Wisconsin-Milwaukee, Milwaukee, WI 53211, USA
}

Correspondence should be addressed to H. Lan; lanhai@hrbeu.edu.cn and S. Wen; wenshuli2010@126.com

Received 24 April 2014; Accepted 11 September 2014

Academic Editor: Kang Li

Copyright (C) 2015 H. Lan et al. This is an open access article distributed under the Creative Commons Attribution License, which permits unrestricted use, distribution, and reproduction in any medium, provided the original work is properly cited.

\begin{abstract}
The consumption of conventional energy sources and environmental concerns have resulted in rapid growth in the amount of renewable energy introduced to power systems. With the help of distributed generations (DG), the improvement of power loss and voltage profile can be the salient benefits. However, studies show that improper placement and size of energy storage system (ESS) lead to undesired power loss and the risk of voltage stability, especially in the case of high renewable energy penetration. To solve the problem, this paper sets up a microgrid based on IEEE 34-bus distribution system which consists of wind power generation system, photovoltaic generation system, diesel generation system, and energy storage system associated with various types of load. Furthermore, the particle swarm optimization (PSO) algorithm is proposed in the paper to minimize the power loss and improve the system voltage profiles by optimally managing the different sorts of distributed generations under consideration of the worst condition of renewable energy production. The established IEEE 34-bus system is adopted to perform case studies. The detailed simulation results for each case clearly demonstrate the necessity of optimal management of the system operation and the effectiveness of the proposed method.
\end{abstract}

\section{Introduction}

Recently an increasing amount of renewable energy is introduced into the local and regional utility grids in order to reduce the serious environmental pollution, improve energy efficiency, and reinforce the power system stability. However, a high penetration of renewable energy raises a problem of system instability, caused by the nature of wind and solar uncertainty. The integration of ESS has become one of the most viable solutions to ensure the stability and power quality of power system with facilitating increased penetration of distributed generation resources.

An optimal management of ESS with distributed generators in power system can achieve significant benefits as follows [1]: (1) enhance power system reliability and power quality; (2) minimize the power loss and improve the voltage profiles; (3) reduce the power system cost and control high cost energy imbalance charges; (4) serve the demand for peak load and decrease the environmental negative influence.

Optimization is an important consideration among the distribution network; in recent years, a few researches have been performed to determine the optimal location and capacity of ESS. The study in [2] presents a smart energy management system to optimize the operation of the microgrid. The system power loss and cost are minimized by the smart management of ESS and operation optimization of distributed generation. The authors in [3] make use of linear programming to develop a new methodology for determining the optimal allocation of embedded generation with respect to the system constraints. In [4], a multiobjective optimization combined with nondominated sorting genetic algorithm is presented to minimize the power generation cost and to maximize the useful life of lead-acid batteries. The research in [5] proposes a new approach based on the cost benefit analysis for optimal sizing of an ESS in microgrid. Two mathematical models have been built for both the islanded and grid-connected modes of microgrid and different operation situations are analyzed. Reference [6] presented an integrated electricity production cost analysis for autonomous electrical networks based on renewable energy sources and energy storage configurations. The initial cost of the energy storage, the input electricity and fuel cost, 


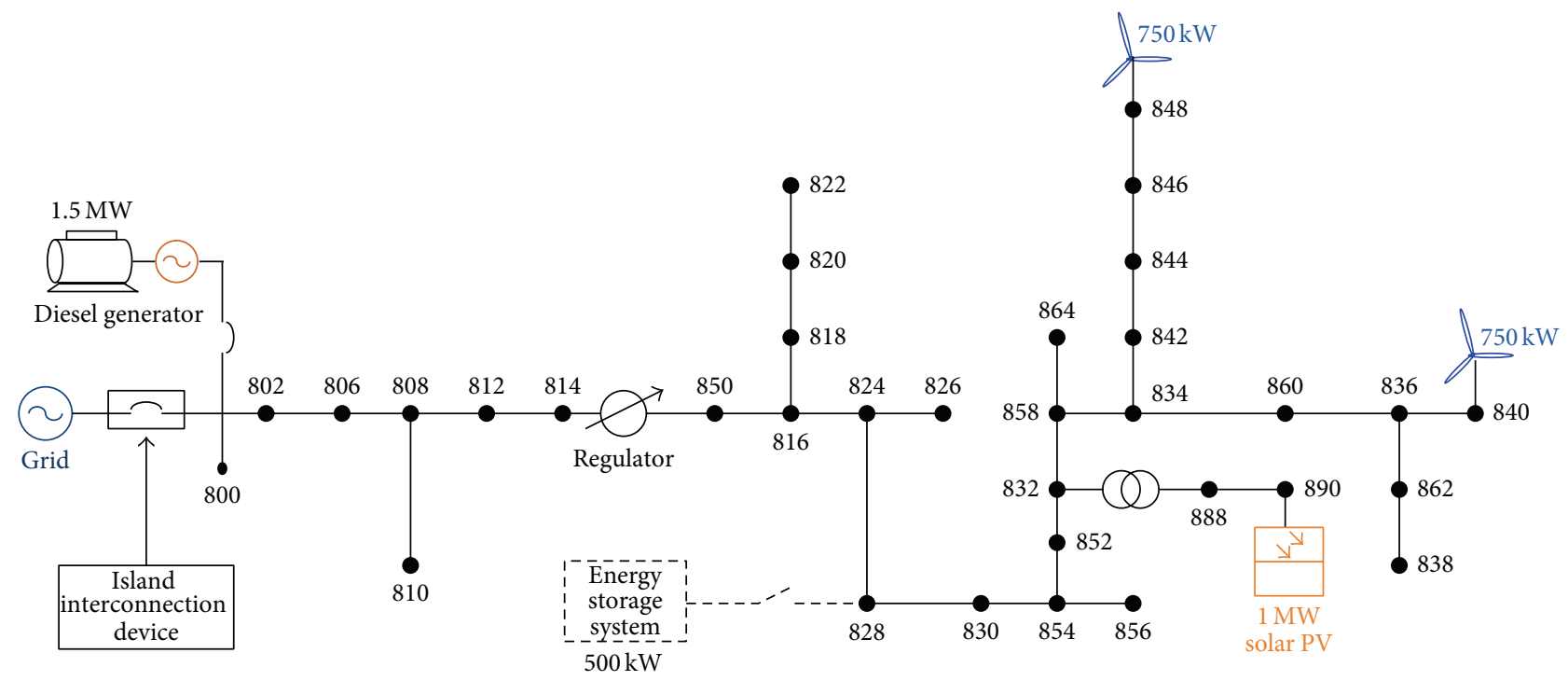

FIGURE 1: The construction of 34-bus microgrid.

and the fixed and variable $\mathrm{M} \& \mathrm{O}$ cost of the entire installation were taken into consideration. A vulnerability assessment for power system planning and operation has been discussed in [7]. The authors in [8] focused on the optimal ESS for maximizing the support to the network voltage control in a distributed system.

Particle swarm optimization has become an efficient tool for solving the nonlinear, nondifferentiable, multiobjective, and discrete variables optimization problems due to its flexible applications and better robustness in controlling parameters. The authors in [9] made use of PSO to achieve the best performance by effectively utilizing controllable loads and ESS. The study in [10] proposed the PSO algorithm to solve economic dispatch problem in a microgrid. With the help of the approach, the system cost, power loss and emission are reduced sharply. The research in [11] employs the PSO technique to search the optimal settings of the optimized parameters for enhancing the microgrid stability. Linear and nonlinear models of a microgrid operating in grid-connected and autonomous modes have been presented. In [12], Lee utilizes PSO approach for optimal wind-battery coordination in a power system. The optimal operating schedule for a battery energy storage system and thermal unit was reached while minimizing the total operation cost. Reference [13] establishes an economic operation model of microgrid including PV, wind energy, heat recovery boiler, and battery. PSO is employed to reduce the emission of pollutant for greenhouse gases and minimize the operation cost. In [14], a novel PSO based on multiagent systems is presented as a solution to the reactive power dispatch problem. A modified PSO based on multiobjective optimization algorithm to solve the energy storage design problem which includes not only energy storage capacity and power rate but also the operation strategy is proposed in [15].

In this paper, a microgrid based on IEEE 34-bus system is set up, which consists of wind power generation system, photovoltaic (PV) generation system, diesel generation system, ESS, and various types of loads. Due to the concern of the power quality and surety in microgrid, particle swarm optimization to allocate the ESS for minimizing the total power loss is proposed. With the help of the optimal allocation of ESSs, the system power loss is dramatically reduced and the voltage profile is improved much. Furthermore, the system reliability is enhanced with a smaller voltage fluctuation. The performance of the microgrid in islanded mode with different operation situation is analyzed in detail and the uncertainty of wind and solar power is taken into consideration.

The rest of this paper is organized as follows. In Section 2, a microgrid configuration based on IEEE 34-bus distribution system is presented and different types of distributed generations are modeled. Section 3 states the problem in formulas. Section 4 proposes the algorithm of PSO. In Section 5, the established 34-bus microgrid system is adopted to implement and verify the proposed algorithm. Several case studies are conducted and compared.

\section{Microgrid Configuration}

2.1. System Structure. Due to its role in driving modern power systems to achieve clean energy generation, the concept of microgrid has been considered more frequently in recent years [16]. A primary goal of a microgrid is to operate a cluster of DGs which are placed in an area power system to provide power and energy with higher reliability, surety, and quality to the local loads. In this paper, a stand-alone 34-bus microgrid is set up for studying the behavior of the renewable energy systems and diesel generator and their effects on the voltage and frequency in a microgrid. The system with the scale of $12 \mathrm{KV}$ and $6 \mathrm{MVA}$ consisting of two $750 \mathrm{KW}$ wind turbines, one $1 \mathrm{MW}$ solar PV, one $1.5 \mathrm{MW}$ diesel generator, and one $500 \mathrm{KW}$ energy storage system is shown in Figure 1. 


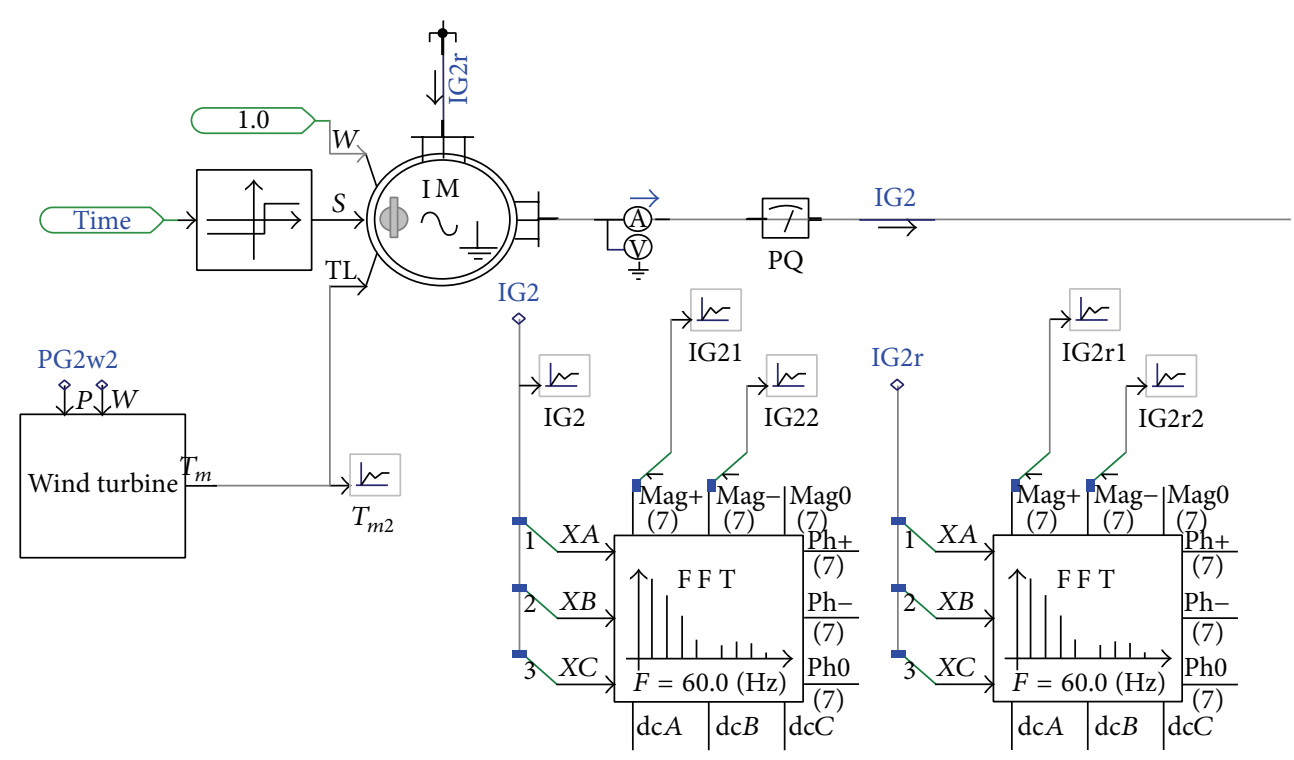

Figure 2: The model for a $750 \mathrm{KW}$ wind generator.

\subsection{Microgrid Components}

2.2.1. Wind Turbine. The large-scale integration of wind power into modern power systems has challenged the wind turbine modeling and analysis innovatively. Accurate modeling of different wind turbine technologies is becoming a necessity as wind turbines replace conventional units in the production side [17]. In the paper, a $750 \mathrm{KW}$ induction wind generator is modeled, which is shown in Figure 2.

2.2.2. Solar $P V$. PV intermittency, or discontinuity of power output, is one of the most important traits used in evaluation and it is often the largest barrier to introducing DGs on a utility system [18], so a detailed solar PV model with maximum power point tracing control method is set up in the paper. The structure of PV model is described in Figure 3.

2.2.3. Diesel Generator. In order to obtain an acceptable efficiency and moderate operation condition, diesel generators are widely used to maintain the voltage in microgrid, especially when more renewable energy generations are introduced into the system. This paper proposes a 1.5 MW synchronous diesel generator model and voltage and frequency drool control is developed, which is shown in Figure 4.

2.2.4. Energy Storage System. Due to the randomness of the natural condition, the output power of renewable energy generations varies drastically and these fluctuations make undesirable effects on the voltage, frequency, and transient stability of the utility grid [19]. In this paper, a $500 \mathrm{KW}$ energy storage system is employed to support the short-term shortcomings of renewable energy and the construction of the ESS model is depicted in Figure 5.
2.2.5. Loads. The system includes a total of 53 loads, consisting of fixed and variable PQ loads and fixed impedance loads. The total microgrid load profile is shown in Figure 6. The maximum load occurs at $7 \mathrm{PM}$ with the capacity of $1100 \mathrm{KW}$, which is selected as a peak load condition to conduct PSO algorithm in case studies.

\section{Problem Formulation}

A higher power loss always occurs in microgrids so it is significant to optimally allocate the ESS. The optimal storage placement and sizing problem is formulated as a constrained nonlinear integer optimization problem with both locations and sizes of storage devices being discrete. The objective function encompasses the total loss of real power, which is restricted by equality and inequality.

3.1. Objective Function. The goal is to minimize the total loss of real power and that of the storage system with improving the voltage profile. The objective function is given by

$$
\min F=P_{\text {loss }}=\sum_{i=1, j \neq i}^{N} G_{i j}\left[V_{i}^{2}+V_{j}^{2}-2 V_{i} V_{j} \cos \left(\delta_{i}-\delta_{j}\right)\right],
$$

where $P_{\text {loss }}$ is the total real power loss (MW); $V_{i}$ is the voltage magnitude at bus $i(\mathrm{pu}) ; \delta_{i}$ is the angle at bus $i$ (degree).

3.2. Constraints. Along with the objective function, there is another important part of the optimization model which needs to be defined and that is the constraints. There are two types of constraints considered in this research: equality and inequality. 


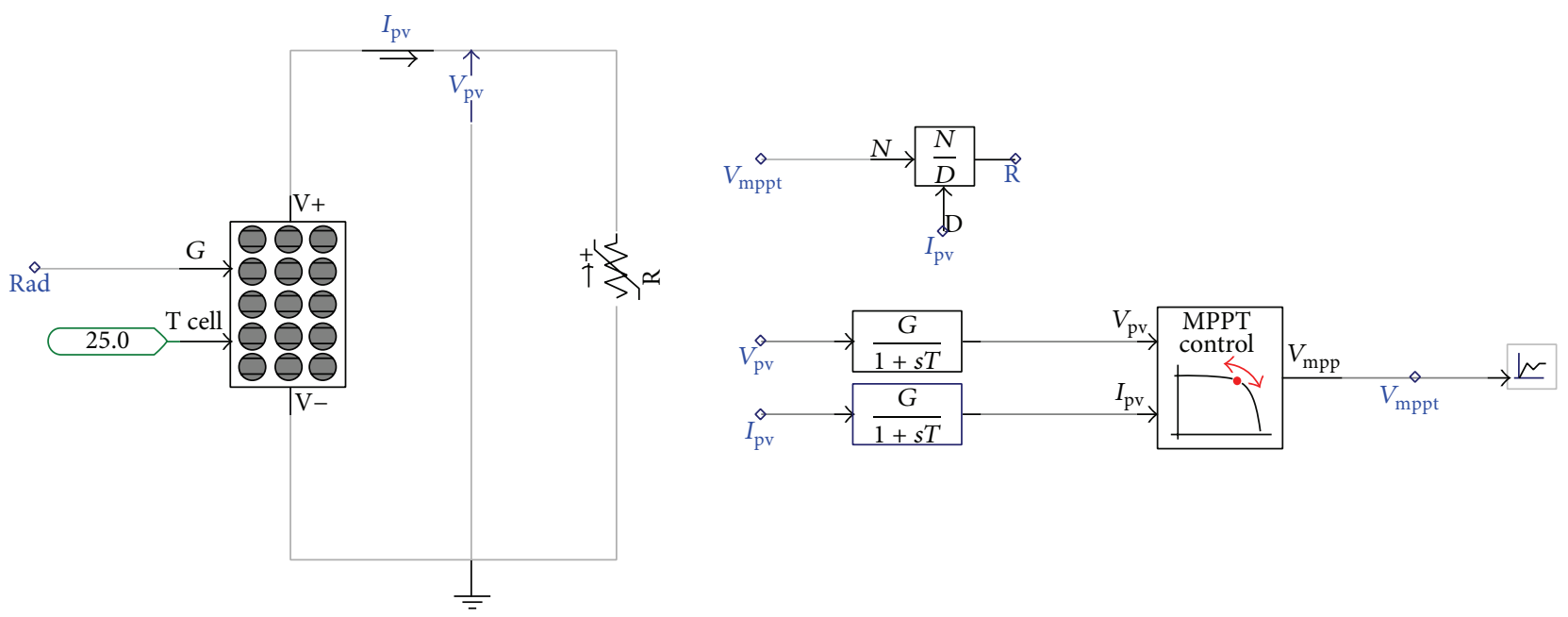

FIgURE 3: The model for 1 MW PV generation system.
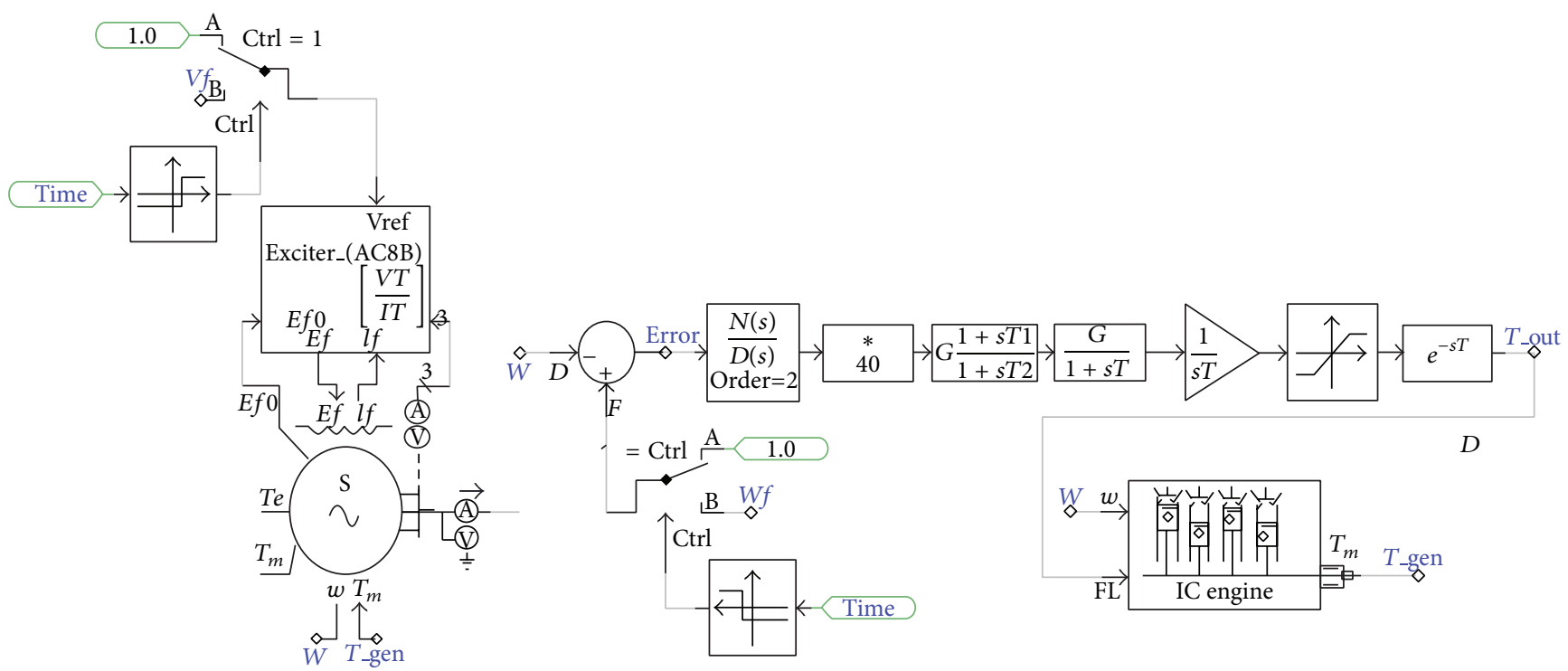

FIGURE 4: Synchronous diesel generation system.
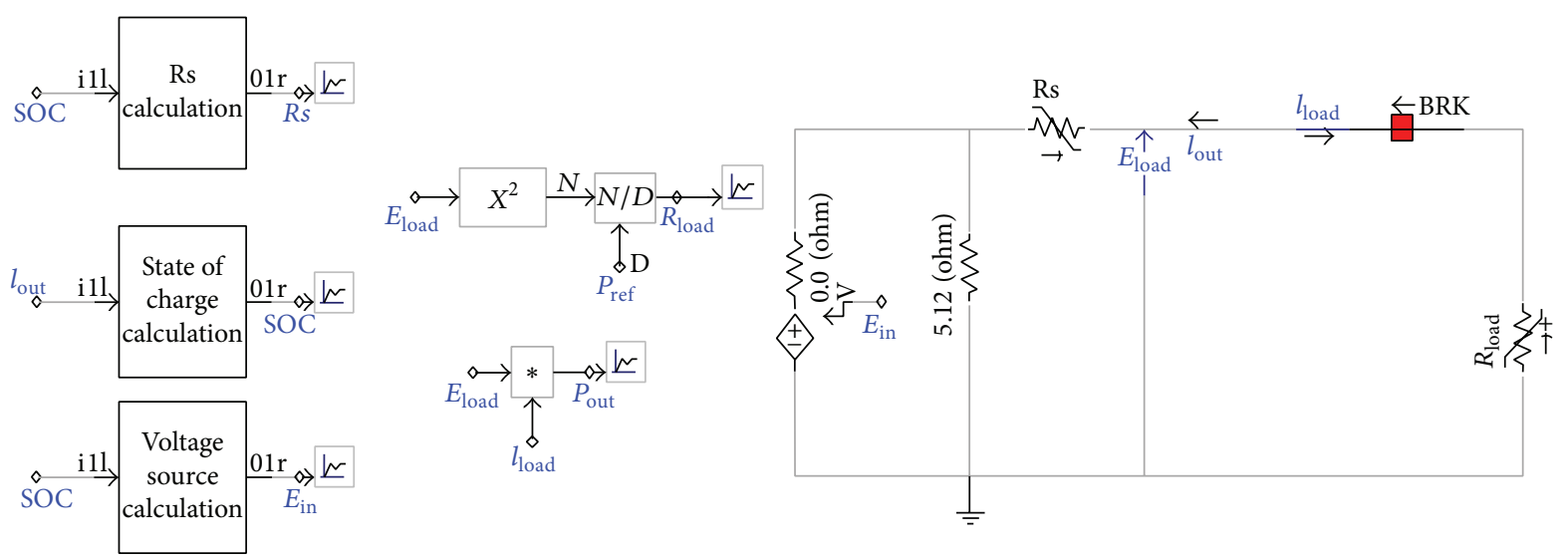

FIGURE 5: $500 \mathrm{KW}$ energy storage system. 


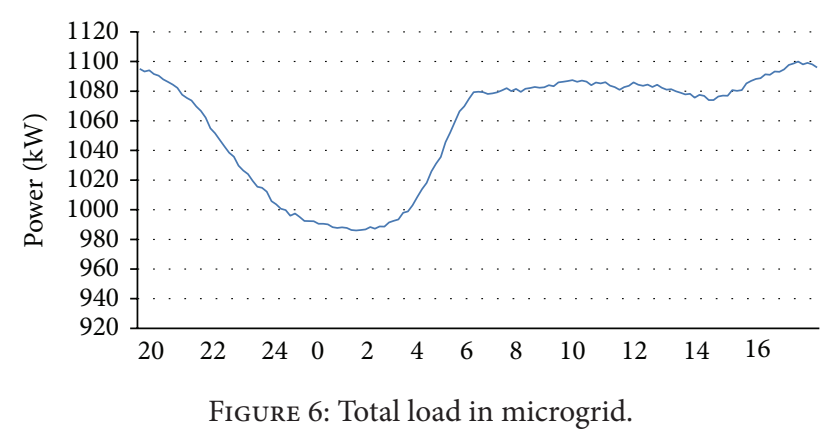

3.2.1. Equality Constraints. These constraints (2) are related to the nonlinear power flow equations

$$
\begin{aligned}
& P_{i}-V_{i} \sum_{j=1}^{N} V_{j}\left(G_{i j} \cos \delta_{i j}+B_{i j} \sin \delta_{i j}\right)=0, \\
& Q_{i}-V_{i} \sum_{j=1}^{N} V_{j}\left(G_{i j} \sin \delta_{i j}-B_{i j} \cos \delta_{i j}\right)=0 .
\end{aligned}
$$

In this paper, simulation analysis for power flow is used to solve the equality constraints.

3.2.2. Inequality Constraints. The inequality constraints are those associated with the bus voltages, the reactive power of generation, and the tap of the transformer. The inequality constraints are shown as follows:

$$
\begin{gathered}
V_{\min } \leq V_{i} \leq V_{\max }, \\
T_{\min } \leq T_{i} \leq T_{\max }, \\
Q_{G \min } \leq Q_{G i} \leq Q_{G \max },
\end{gathered}
$$

where $V_{i}$ is the RMS value of the bus $i$ voltage; $T_{i}$ is the tap of transformer $i$; $Q_{G i}$ is the reactive power of generator $i$.

\section{Solution Method}

PSO is a heuristic optimization technique first developed in 1995 by Kennedy and Eberhart [20, 21]. The original objective of their research was to mathematically simulate the social behavior of bird flocks and fish schools. The fundamental idea behind the PSO algorithm is that a population called a swarm is randomly generated, consisting of individuals called particles. Each particle, representing a potential solution of the optimization problem, flies through an $\mathrm{N}$-dimensional search space at a random velocity and updates its position based on its own best exploration, best swarm global experience, and its previous velocity vector according to the following equations:

$$
\begin{gathered}
v_{i}^{k+1}=w v_{i}^{k}+c_{1} r_{1}\left(p_{\text {besti }}^{k}-x_{i}^{k}\right)+c_{2} r_{2}\left(g_{\text {best }}^{k}-x_{i}^{k}\right), \\
x_{i}^{k+1}=x_{i}^{k}+v_{i}^{k+1},
\end{gathered}
$$

where $w$ is the inertia weight; $c_{1}$ and $c_{2}$ are acceleration constants; $r_{1}$ and $r_{2}$ are two random numbers in the range of $[0,1] ; p_{\text {best } i}^{k}$ is the best position particle $i$ achieved based on its own experience, $p_{\text {best } i}^{k}=\left[x_{i 1}^{p_{\text {best }}}, x_{i 2}^{p_{\text {best }}}, \ldots ., x_{i N}^{p_{\text {best }}}\right] ; g_{\text {best }}^{k}$ is the best particle position based on overall swarm's experience, $g_{\text {best }}^{k}=\left[x_{1}^{g_{\text {best }}}, x_{2}^{g_{\text {best }}}, \ldots, x_{N}^{g_{\text {best }}}\right]$.

In order to improve the efficiency and accuracy, a linearly decreasing inertia weight from maximum $w_{\max }$ value to $w_{\min }$ is applied to update the inertia weight [22]:

$$
w^{k}=w_{\max }-\frac{w_{\max }-w_{\min }}{k_{\max }} \cdot k,
$$

where $w_{\max }$ and $w_{\min }$ are the initial and final inertia weights and $k_{\max }$ is the maximum iteration number.

In this paper, by combining the PSCAD simulation and MATLAB programming, the particle swarm optimization algorithm is developed to search the best combination of the placements and sizes of energy storage devices in the microgrid. A mixed integer PSO is applied to optimally locate and rate the storage. The developed PSO algorithm starts with randomly generating a swarm for initializing diesel generator's voltage, output power and position, and size of ESS. The random selections of swarm of particles considering constraints and corresponding velocity for each particle are initialized. Through running the 34-bus microgrid in PSCAD, particles are evaluated by objective function, and recalls their best solutions associated with the best fitness value. After checking and preserving the $p_{\text {best }}$ and $g_{\text {best }}$, if the algorithm has not yet searched the minimum loss, the position and velocity of each particle are continuously updated. The algorithm will output the optimal allocation of ESS till the best result has been found. The flowchart shown in Figure 7 illustrates the proposed PSO algorithm.

\section{Results and Discussion}

The established 34-bus microgrid system shown in Figure 1 is selected to perform the proposed algorithm. The system consists of 4 generations and 58 loads, where bus 800 is diesel generation system, bus 840 and 848 are two wind power generation systems, bus 890 is solar PV system, and other buses are load nodes.

The impacts of the integration of renewable energy and energy storage systems in two cases are studied and compared to demonstrate the effectiveness of the proposed PSO method. The voltage profiles and the output power of diesel generator and ESS are shown in Tables 1 and 2.

Case 1. A regular power flow simulation analysis for the system under consideration of the minimum of the renewable energy and the maximum of the load.

Case 2. PSO with distributed ESS considering the worst operation condition.

It can be seen from Table 1 that when the renewable energy source is reduced and one conventional $500 \mathrm{KW}$ ESS is installed, the system will confront with low voltage problem in Case 1. Even though diesel generation system supplies more power to support the system, the voltages at bus 820 , bus 822 , 


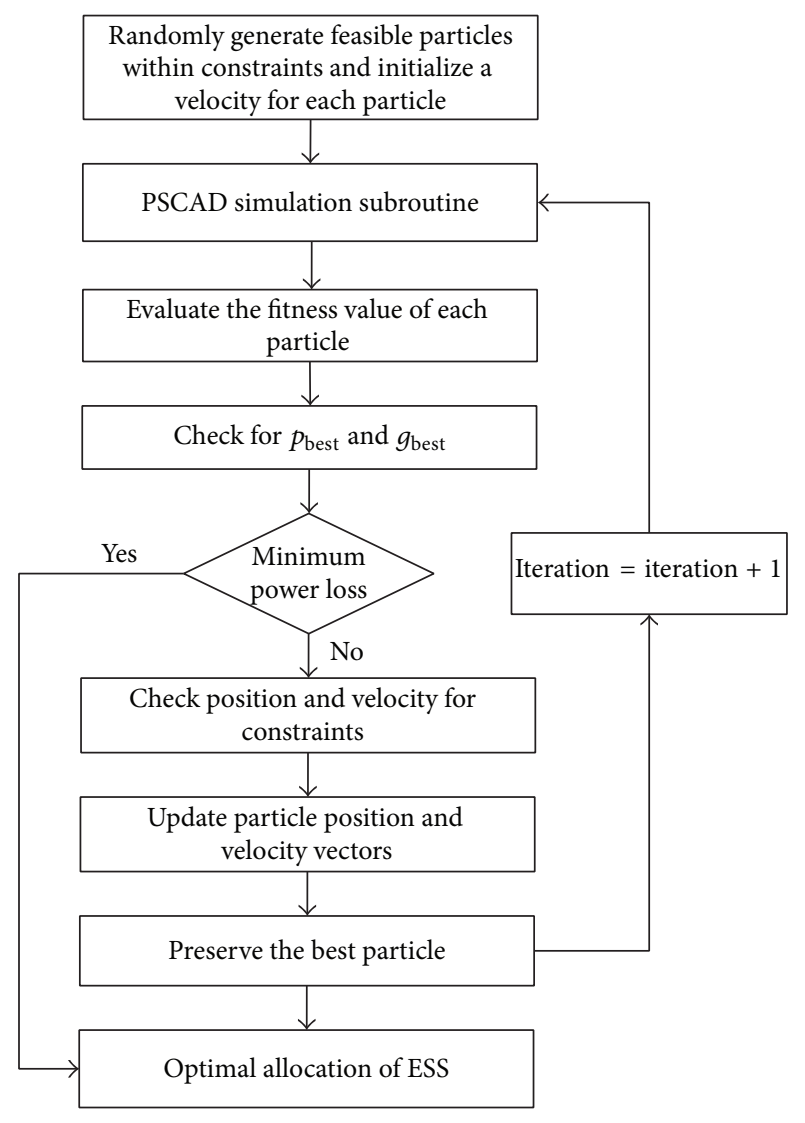

FIgURE 7: The flowchart of the proposed PSO.

TABLE 1: Voltage profiles in Cases 1 and 2.

\begin{tabular}{lccccc}
\hline Bus & $\begin{array}{c}\text { Case 1 } \\
\text { Voltage } \\
(\mathrm{pu})\end{array}$ & $\begin{array}{c}\text { Case 2 } \\
\text { Voltage } \\
(\mathrm{pu})\end{array}$ & Bus & $\begin{array}{c}\text { Case 1 } \\
\text { Voltage } \\
(\mathrm{pu})\end{array}$ & $\begin{array}{c}\text { Case 2 } \\
\text { Voltage } \\
(\mathrm{pu})\end{array}$ \\
\hline $\mathbf{8 0 0}$ & $\mathbf{0 . 9 9 8 9}$ & $\mathbf{0 . 9 9 8 9}$ & 856 & 0.9982 & 1 \\
802 & 0.9969 & 0.9987 & 852 & 0.9806 & 1.007 \\
806 & 0.9957 & 0.9986 & 832 & 0.9806 & 1.007 \\
808 & 0.9732 & 0.9977 & 888 & 0.9517 & 0.9812 \\
810 & 0.9776 & 0.9987 & $\mathbf{8 9 0}$ & $\mathbf{0 . 9 2 4 7}$ & $\mathbf{0 . 9 7 2 7}$ \\
812 & 0.9506 & 0.9973 & 858 & 0.9834 & 1.012 \\
814 & 0.9375 & 0.9973 & 864 & 0.9879 & 0.9719 \\
850 & 1.014 & 0.9973 & 834 & 0.987 & 1.018 \\
816 & 1.014 & 0.9973 & 842 & 0.987 & 1.011 \\
818 & 0.9966 & 0.9827 & 844 & 0.9871 & 1.018 \\
820 & 0.9473 & 0.9799 & 846 & 0.9886 & 1.02 \\
822 & 0.9419 & 0.9757 & $\mathbf{8 4 8}$ & $\mathbf{0 . 9 8 8 8}$ & $\mathbf{1 . 0 2 1}$ \\
824 & 1.013 & 0.9987 & 860 & 0.9883 & 1.019 \\
826 & 1.011 & 1.011 & 836 & 0.9904 & 1.022 \\
828 & 1.014 & 0.999 & $\mathbf{8 4 0}$ & $\mathbf{0 . 9 9 1 2}$ & $\mathbf{1 . 0 2 3}$ \\
830 & 0.997 & 1.001 & 862 & 0.9904 & 1.022 \\
854 & 0.9967 & 1.001 & 838 & 0.9893 & 1.013 \\
\hline
\end{tabular}

and bus 890 in Case 1 still drop below $0.95 \mathrm{pu}$. Due to the improper size and placement of ESS in Case 1, the system faces

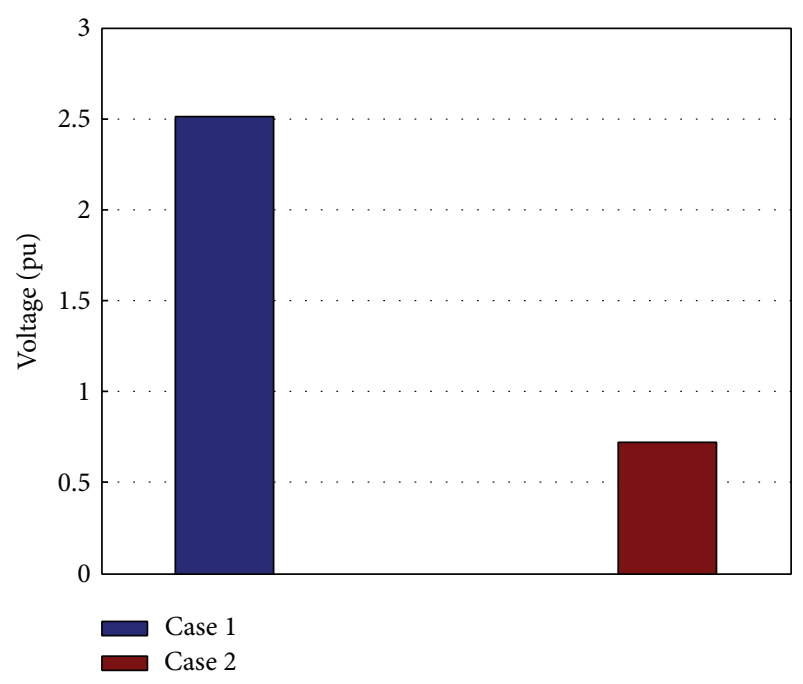

Figure 8: The voltage deviation for Cases 1 and 2.

instability problem accompanied by a large power loss which is $378 \mathrm{KW}$. However, with the help of distributed ESS, the voltage profiles in Case 2 are improved much and the system no longer faces voltage problem with less voltage violation. Furthermore, in Case 2, the best placement to install ESSs is buses 814,828 , and 832 with sizes of $183.3 \mathrm{KW}, 220.2 \mathrm{KW}$, and $22.7 \mathrm{KW}$, respectively. As a result, the system has minimum power loss. Comparing with Case 1, the total power loss in Case 2 is dramatically reduced to be $113.8 \mathrm{KW}$, which is $69.9 \%$ less than that $(378 \mathrm{KW})$ in Case 1 . In addition, the total size of ESS is $426.2 \mathrm{KW}$ in Case 2 which is enough to maintain the system stability when the renewable energy is 0 , which is $73.8 \mathrm{KW}$ less than that $(500 \mathrm{KW})$ in the original plan, and it demonstrates that the calculated ESS allocations in Case 1 tend to overcompensate the voltage when applied to the entire wind and solar distribution. Another phenomenon worthy to be noted is that the voltage profile has less fluctuation with distributed ESS and all the voltages are within voltage constraints which proves that the system has a strong stability. The voltage deviation is computed by

$$
f=\sum_{k=1}^{n}\left(\frac{V_{k}-V_{k}^{\mathrm{spec}}}{\Delta V_{k}^{\max }}\right)^{2},
$$

where $V_{k}^{\text {spec }}$ is the expected voltage; $\Delta V_{k}^{\max }$ is the maximum of voltage deviation.

The comparison of voltage deviation for two cases is shown in Figure 8, where one can easily conclude that the voltages in Case 1 tend to fluctuate higher than those in Case 2.

\section{Conclusion}

As renewable energy penetration continues to increase in the power grids, it becomes important to consider the uncertainty of wind and solar power when optimizing the placement and size of energy storage systems. In the paper, a 34-bus microgrid consisting of wind power generation 
TABLE 2: Output power of diesel generator and ESS.

\begin{tabular}{|c|c|c|c|c|c|c|c|c|}
\hline & \multicolumn{4}{|c|}{ Diesel } & \multicolumn{4}{|c|}{ Allocation of ESS } \\
\hline & Bus & $V(\mathrm{pu})$ & $P(\mathrm{KW})$ & $Q$ (KVA) & Bus & $V(\mathrm{pu})$ & $P(\mathrm{KW})$ & $Q$ (KVA) \\
\hline Case 1 & 800 & 0.9989 & 1478 & 721.3 & 828 & 1.014 & -1.1 & 160.4 \\
\hline \multirow{3}{*}{ Case 2} & & & & & 814 & 0.9973 & 183.3 & -1.1 \\
\hline & 800 & 0.9989 & 1008 & 638.5 & 828 & 0.999 & 1.1 & 220.2 \\
\hline & & & & & 832 & 1.007 & 21.4 & -22.7 \\
\hline
\end{tabular}

system, photovoltaic generation system, diesel generation system, and energy storage system is set up for studying the performance of distributed generations and their effects on power systems. To optimize the microgrid operation, the PSO algorithm is proposed to select the best allocation of ESS and determine the output of diesel generation system. The paper gives out optimization results for each case. It can be concluded as follows. (i) The proposed PSO is well developed for finding proper placement and size of ESS. (ii) The total real power loss is minimized, and voltage profiles are improved by properly installing ESS to the system. (iii) Distributed ESS tends to be better than centralized ESS.

\section{Conflict of Interests}

The authors declare that there is no conflict of interests regarding the publication of this paper.

\section{References}

[1] Q. Fu, L. F. Montoya, A. Solanki et al., "Microgrid generation capacity design with renewables and energy storage addressing power quality and surety," IEEE Transactions on Smart Grid, vol. 3, no. 4, pp. 2019-2027, 2012.

[2] C. Chen, S. Duan, T. Cai, B. Liu, and G. Hu, "Smart energy management system for optimal microgrid economic operation," IET Renewable Power Generation, vol. 5, no. 3, pp. 258-267, 2011.

[3] A. Keane and M. O'Malley, "Optimal allocation of embedded generation on distribution networks," IEEE Transactions on Power Systems, vol. 20, no. 3, pp. 1640-1646, 2005.

[4] B. Zhao, X. Zhang, J. Chen, C. Wang, and L. Guo, "Operation optimization of standalone microgrids considering lifetime characteristics of battery energy storage system," IEEE Transactions on Sustainable Energy, vol. 4, no. 4, pp. 934-943, 2013.

[5] S. X. Chen, H. B. Gooi, and M. Q. Wang, "Sizing of energy storage for microgrids," IEEE Transactions on Smart Grid, vol. 3, no. 1, pp. 142-151, 2012.

[6] J. K. Kaldellis and D. Zafirakis, "Optimum energy storage techniques for the improvement of renewable energy sourcesbased electricity generation economic efficiency," Energy, vol. 32, no. 12, pp. 2295-2305, 2007.

[7] J.-H. Teng, C.-Y. Chen, and I. C. Martinez, "Utilising energy storage systems to mitigate power system vulnerability," IET Generation, Transmission and Distribution, vol. 7, no. 7, pp. 790798, 2013.

[8] M. Nick, M. Hohmann, R. Cherkaoui, and M. Paolone, "On the optimal placement of distributed storage systems for voltage control in active distribution networks," in Proceedings of the $3 \mathrm{rd}$ IEEE PES Innovative Smart Grid Technologies Europe (ISGT '12), pp. 1-6, October 2012.
[9] E. Sortomme and M. A. El-Sharkawi, "Optimal power flow for a system of microgrids with controllable loads and battery storage," in IEEE/PES Power Systems Conference and Exposition (PSCE '09), pp. 1-5, March 2009.

[10] A. K. Basu, A. Bhattacharya, S. Chowdhury, and S. P. Chowdhury, "Planned scheduling for economic power sharing in a CHP-based micro-grid," IEEE Transactions on Power Systems, vol. 27, no. 1, pp. 30-38, 2012.

[11] M. A. Hassan and M. A. Abido, "Optimal design of microgrids in autonomous and grid-connected modes using particle swarm optimization," IEEE Transactions on Power Electronics, vol. 26, no. 3, pp. 755-769, 2011.

[12] T.-Y. Lee, "Optimal wind-battery coordination in a power system using evolutionary iteration particle swarm optimisation," IET Generation, Transmission and Distribution, vol. 2, no. 2, pp. 291-300, 2008.

[13] X. Wu and X. Wang, "Optimal management of microgrid using particle swarm optimization algorithm," in Proceedings of the Annual Conference on Electrical and Control Engineering (ICECE '11), pp. 1141-1144, Yichang, China, September 2011.

[14] B. Zhao, C. X. C. Guo, and Y. J. Cao, "A multiagent-based particle swarm optimization approach for optimal reactive power dispatch," IEEE Transactions on Power Systems, vol. 20, no. 2, pp. 1070-1078, 2005.

[15] Y. Xu and C. Singh, "Multi-objective design of energy storage in distribution systems based on modified particle swarm optimization," in Proceedings of the IEEE Power and Energy Society General Meeting (PES '12), pp. 1-8, July 2012.

[16] M. Agrawal and A. Mittal, "Micro grid technological activities across the globe: a review," International Journal of Research and Reviews in Applied Sciences, vol. 7, pp. 147-152, 2011.

[17] I. D. Margaris and N. D. Hatziargyriou, "Direct drive synchronous generator wind turbine models for power system studies," in Proceedings of the 7th Mediterranean Conference and Exhibition on Power Generation, Transmission, Distribution and Energy Conversion (MedPower '10), pp. 1-7, November 2010.

[18] G. J. Shirek and B. A. Lassiter, "Photovoltaic power generation: modeling solar plants' load levels and their effects on the distribution system," IEEE Industry Applications Magazine, vol. 19, no. 4, pp. 63-72, 2013.

[19] A. Esmaili and A. Nasiri, "Power smoothing and power ramp control for wind energy using energy storage," in Proceedings of the 3rd Annual IEEE Energy Conversion Congress and Exposition (ECCE '11), pp. 922-927, Phoenix, Ariz, USA, September 2011.

[20] J. Kennedy and R. Eberhart, "Particle swarm optimization," in Proceedings of the IEEE International Conference on Neural Networks, pp. 1942-1948, Piscataway, NJ, USA, December 1995.

[21] R. Eberhart and J. Kennedy, "New optimizer using particle swarm theory," in Proceedings of the 6th International Symposium on Micro Machine and Human Science, pp. 39-43, October 1995. 
[22] D. C. Huynh and M. W. Dunnigan, "Parameter estimation of an induction machine using advanced particle swarm optimisation algorithms," IET Electric Power Applications, vol. 4, no. 9, pp. 748-760, 2010. 


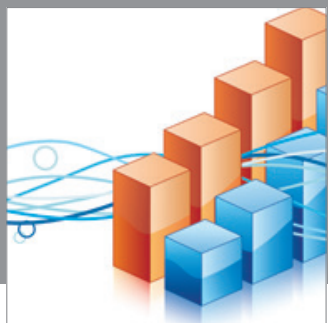

Advances in

Operations Research

mansans

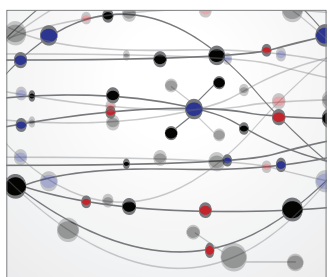

The Scientific World Journal
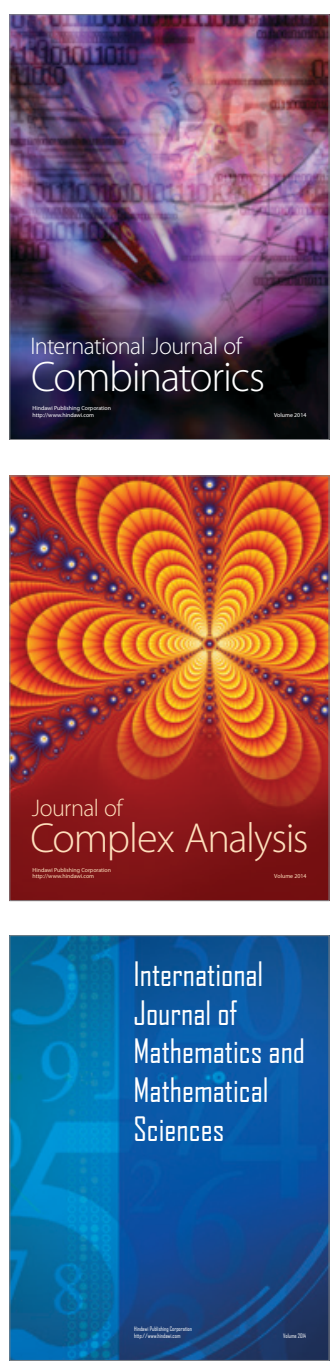
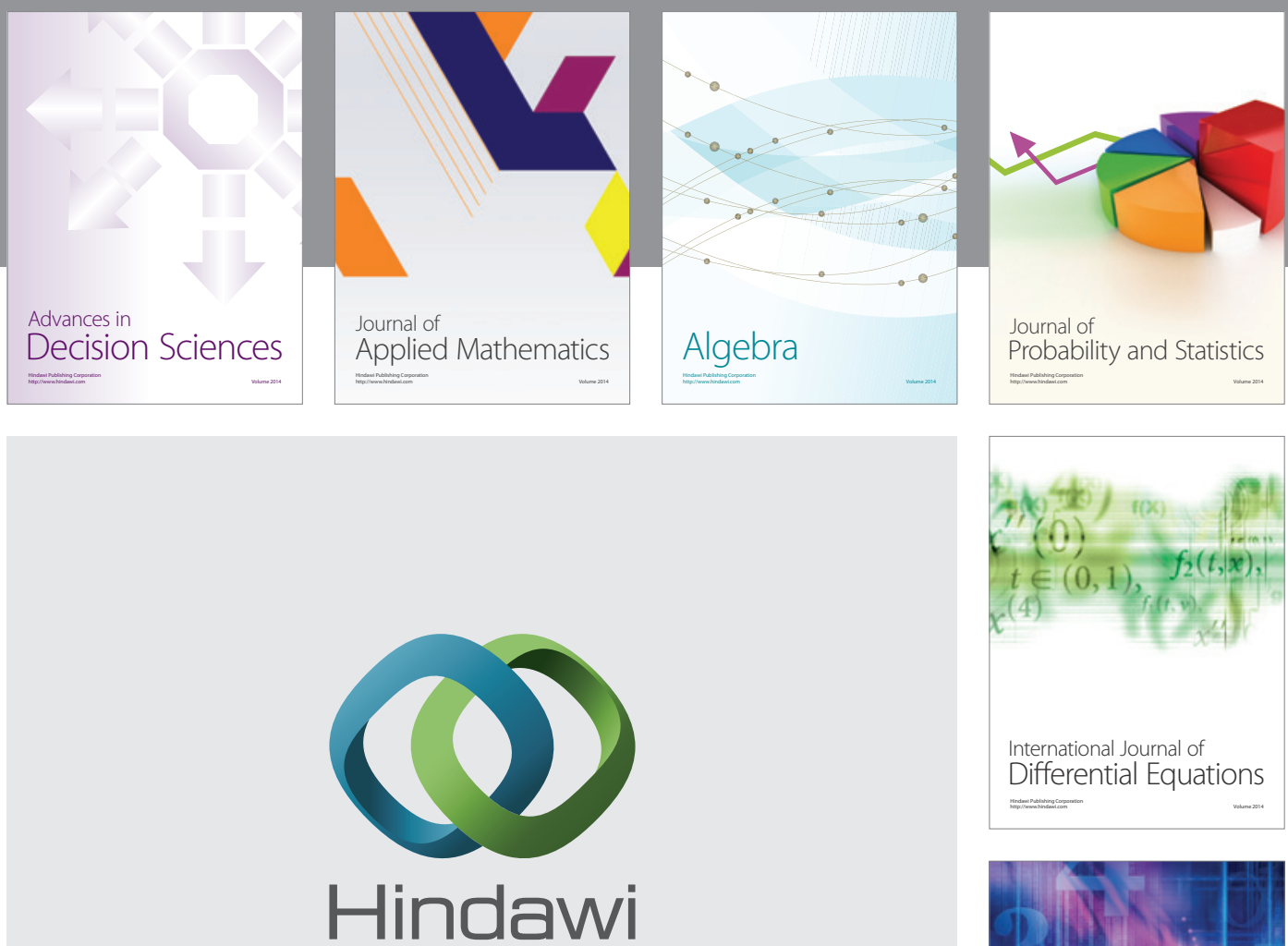

Submit your manuscripts at http://www.hindawi.com
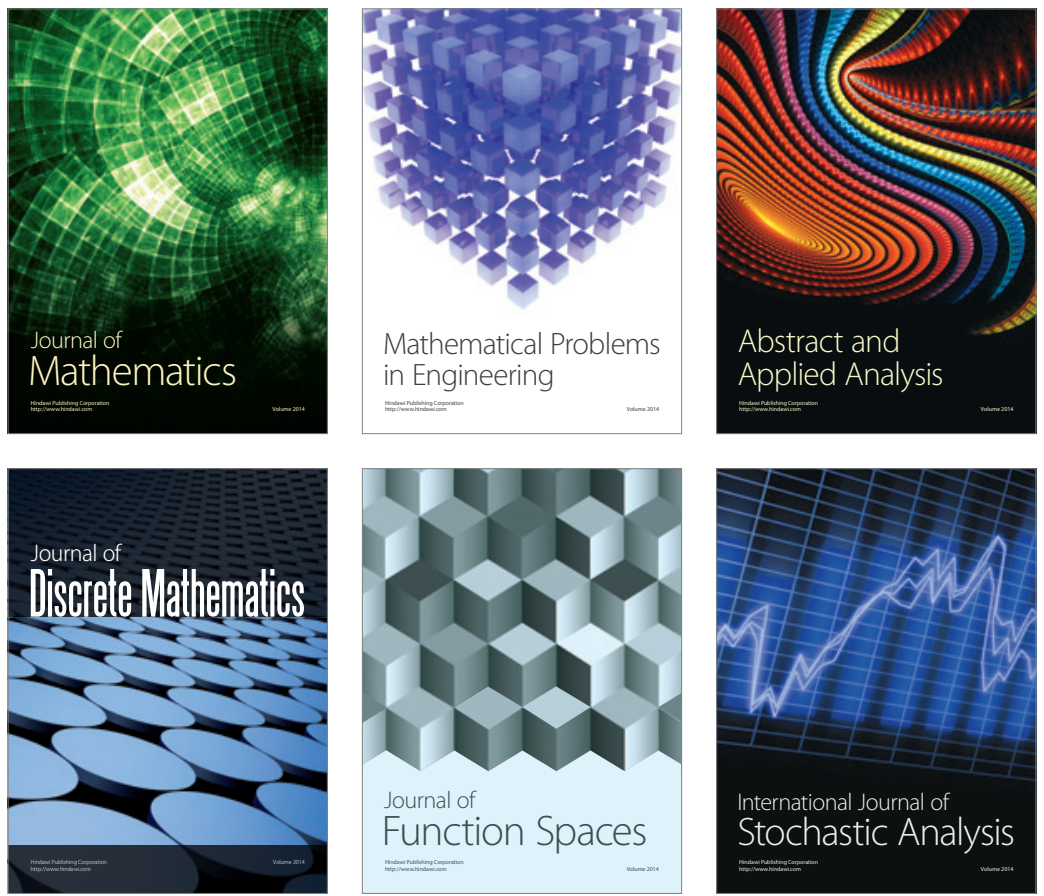

Journal of

Function Spaces

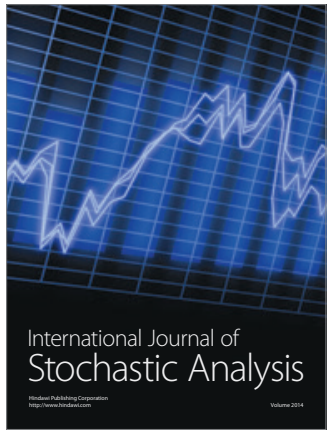

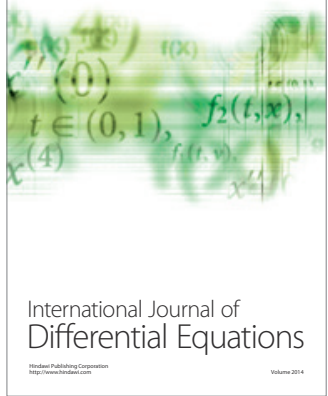
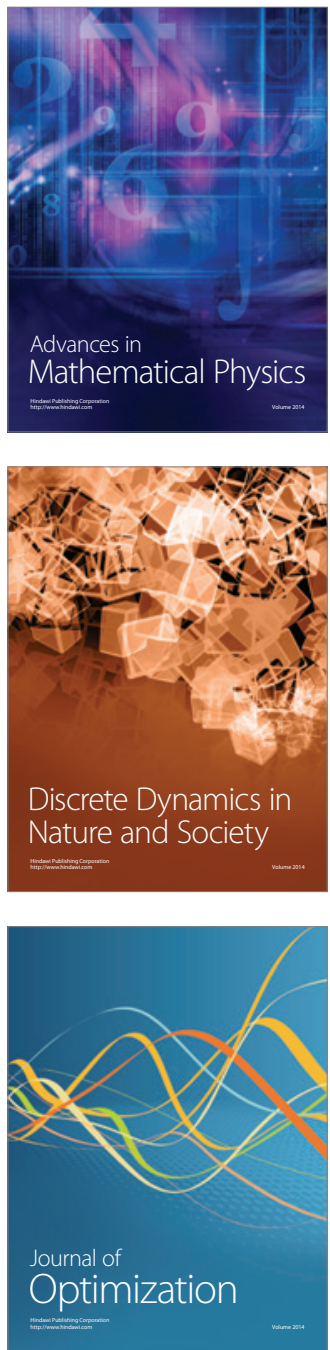